\title{
Patients' Satisfaction and Its Determinants in Outpatient and Inpatient Departments of Tertiary Hospitals in Ghana: A Literature Review
}

\author{
Article by Jones Akuamoah-Boateng \\ PhD in Healthcare Administration, Texila American University \\ E-mail: jaboateng@texilaconnect.com
}

\begin{abstract}
Healthcare systems and particularly tertiary hospitals are the centre of patient care delivery and represent an organizational hub of the bigger healthcare provider network. One of the most important objectives of any health system is patient satisfaction, yet there is considerable difficulty in the measurement of satisfaction and gauge the responsiveness of healthcare systems. Patient satisfaction is influenced not only by clinical factors but also non-clinical factors and outcomes which are usually ignored by healthcare providers and administrators in developing countries. Extensive research revealed that, there have not been studies that have looked at how patient satisfaction is influenced differentially by clinical factors (core services) and non-clinical factors (health system) and outcomes in Ghana. Also, the objects of the studies carried out in Ghana have been outpatients' service experience and no study has focused on adding inpatients' service experience in measuring the level of service quality delivered by tertiary hospitals. The purpose of this article is to propose that both clinical factors and non-clinical factors influence the satisfaction of patients who utilize the outpatient and inpatient departments of tertiary hospitals in Ghana hence healthcare providers and administrators should consider not only clinical factors as determinants of patient satisfaction but also non-clinical factors.
\end{abstract}

Keywords: Satisfaction, Determinants, Inpatient, Outpatient, clinical, non-clinical.

\section{Introduction}

One of the most important objectives of any health system is patient satisfaction. According to Desta et al., (2018) the perspective of the patient's view is becoming more integrated in the process of improving healthcare systems. Patient satisfaction is the health care recipient's reaction to salient aspects of the context, process, and result of their service experiences. It consists of a cognitively based evaluation or grading of directly-received services including structure, process, and outcome of services and an affectively based response to the structure, process, and outcome of services.

In general, patient satisfaction has been defined as an evaluation that reflects the perceived differences between expectations of the patient to what is actually received during the process of care. It is both a service quality indicator and a quality component. Despite its importance, there is considerable difficulty in the measurement of patient satisfaction and gauge the responsiveness of health care systems. This is because patient satisfaction is influenced not only by clinical factors but also non-clinical factors and outcomes which are usually ignored by health care providers and administrators in developing countries (Sanjeewa and Senevirathne, 2017). According to Baalbaki, et al., (2014) patient satisfaction is influenced by many factors which include: quality of clinical (core) services provided, availability of drugs, behaviour of doctors and other health care professionals, cost of services, physical comfort of patients at the hospital, emotional support given to patients, respect for patient preferences and level of hospital infrastructure. They noted that a mismatch of service expectations of patients and quality of health care service received leads to decreased satisfaction, therefore assessing the perspectives of patients gives them the voice which provides the important input to make public health services more responsive to patient needs and expectations. 
DOI: 10.21522/TIJMG.2015.SE.19.01.Art015

ISSN: 2520-310X

In spite of all the commitment of the Ghana government, the Ghana Health Service and Donor agencies as well as other stakeholders to improve the level of quality of health care services in the country, there is still a strong perception of unsatisfactory services provided by health professionals in public health facilities in the areas of relationship with patients, care and treatment, consent and confidentiality of patients, access to basic information about their rights and sanitation of working environment, (MOH, 2007).

\section{Research gap}

Ghana's Ministry of Health $(\mathrm{MOH})$ has over the years concerned itself with quality of healthcare which yields patient satisfaction. However, pace of quality improvements has been slow and objectives have not been met. According to Ahenkan and Aduo-Adjei (2017) this is the result of inadequate priority given to improvement of healthcare quality. In lieu of this, there is the growing need to research into quality of health service delivery in the country especially with respect to patient satisfaction which is a key indicator of and integration of quality assurance in Ghana's health care system and facilities. In Ghana many of the studies of health care quality have focused on service quality dimensions. Also studies conducted in public hospitals in Ghana have provided empirical evidence of inadequate level of quality of health care services both in terms of objective measures of patient opinions and that of health care providers (Ahenkan and Aduo-Adjei, 2017) In addition other studies have found that long waiting times, frequent shortage of medicines and poor attitudes of healthcare providers as contributing to poor quality services and consequently patient dissatisfaction with health care in Ghana (Essiam, 2013). Extensive research revealed that, there have not been studies that have looked at how patient satisfaction is influenced differentially by clinical factors (core services) and non-clinical (health system) factors and outcomes. Also, the objects of the studies carried out in Ghana have been outpatients' service experience and no study has focused on adding inpatients service experience in measuring the level of service quality delivered by hospitals. (Essiam, 2013, Ahenkan and Aduo-Adjei, 2017).

According to Baalbaki, et al., (2008), there is increasing gap between patients' systematic demands and hospital core performance and therefore, the need to understand patient needs in the hospital environment. They noted that patient satisfaction in healthcare is important for the sustained profitability of hospitals, increased efficiency and effectiveness as well as better treatment outcomes. While hospitals in Ghana are continuously improving their image and services, it is important to differentiate between core clinical services and non-core services. Baalbaki (2014) noted that although core services provided by hospitals are necessary for patient satisfaction, they do not solely determine it. Non-core health system factors such as customer services are also important. As a result, there exists conceptual gap as well as tangible need to differentiate patient health care system and core service assessments. To do this assessment research has shown that it is more reliable to rely on post patient discharge surveys both for outpatients and in patients rather than when patients are in the hospital. In view of this, the continuous monitoring and evaluation of views on the quality of healthcare is important for quality improvement commitments.

\section{Objective and research methodology}

The purpose of this article is to propose that both clinical factors and non-clinical factors influence the satisfaction of patients who utilize the outpatient and inpatient departments of tertiary hospitals in Ghana; hence healthcare providers and administrators when embarking on improvement to achieve quality healthcare should consider not only clinical factors as determinants of patient satisfaction but also nonclinical factors.

Literature reviewed in this paper was sourced from the general internet search engines, text books, health reports and peer reviewed journals.

\section{Limitations}

There are limitations to this review of literature. Research was limited to peer-reviewed journals (online), internet search engines, health reports and text books. 


\section{Literature review}

\section{Conceptual model}

The conceptual model is based on the model that patient satisfaction in health care services is influenced by both core clinical services and non-core health delivery system. The satisfaction or dissatisfaction with the entire healthcare service encounter is a function of the sum of all experiences in relevant service category sets.

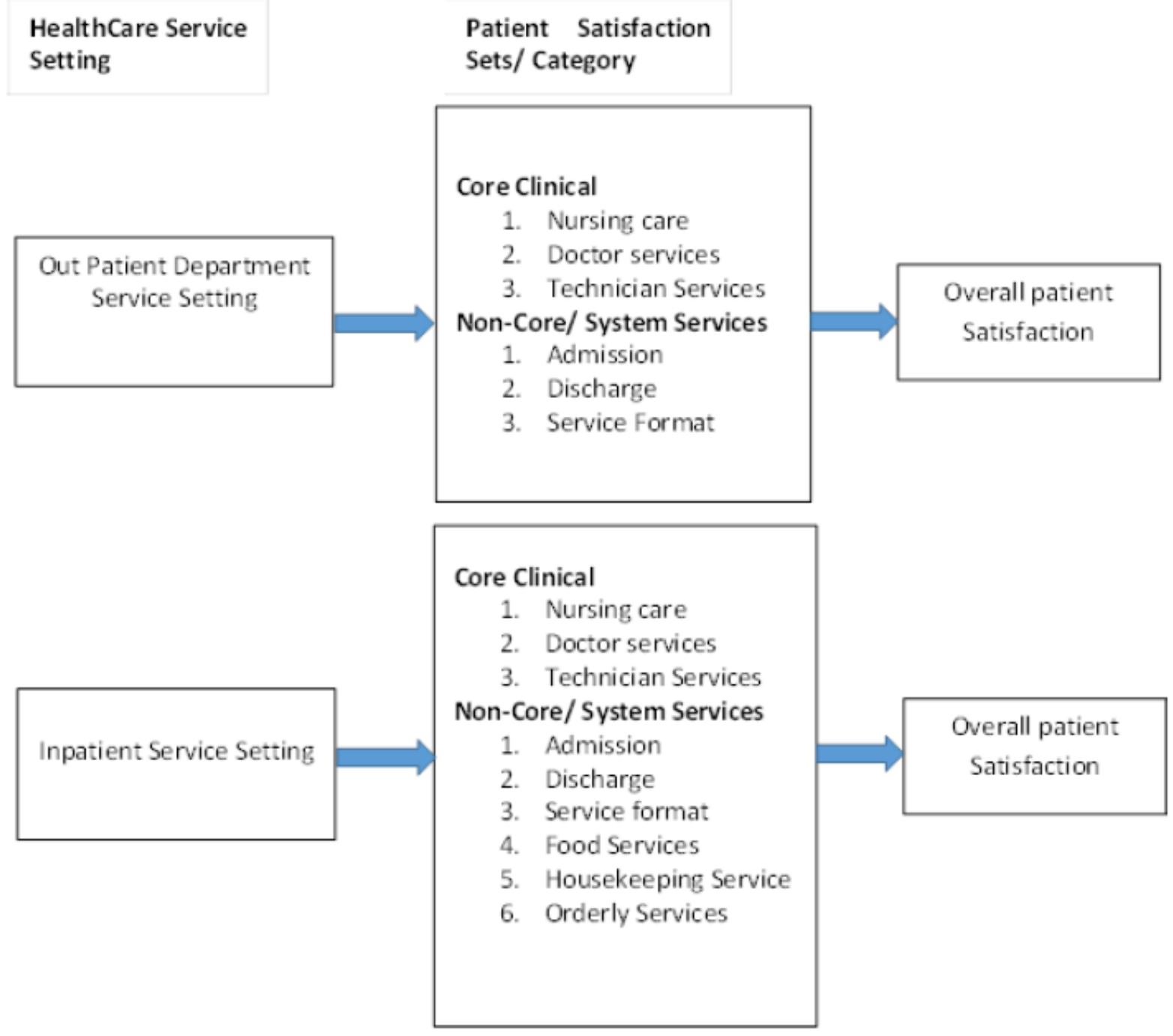

(Sanjeewa and Senevirathne, 2017)

Figure 1. Conceptual Framework

\section{Outpatient department}

Outpatient department (OPD) is the first point of contact of the hospital with patients and serves as the shop window to any healthcare service provided to the community. The care in the OPD is believed to indicate the quality of services of a hospital and is reflected by patients' satisfaction with the services being provided. 
DOI: 10.21522/TIJMG.2015.SE.19.01.Art015

ISSN: 2520-310X

There are two types of OP Services -

1. Centralized Outpatient Services: All services are provided in a compact area which includes all diagnostic and therapeutic facilities being provided in the same place.

2. Decentralized Outpatient Services: Services are provided in the respective departments.

3. According to Tabish (2011), the functions of the OPD include:

4. Early diagnosis, curative, preventive \& rehabilitative care on ambulatory basis

5. Effective treatment on ambulatory basis

6. Screening for admission to hospital

7. Follow up care \& care after discharge

8. Promotion of health by health education

9. Promotion of health through health education

10. Training of medical / nursing students

11. Keeping up to date records for future treatment, medical education, epidemiological and social research

12. Rendering of preventive health care

\section{Inpatient department}

Inpatient care is the care of patients whose condition requires admission to a hospital. Progress in modern medicine and the advent of comprehensive out-patient clinics ensure that patients are only admitted to a hospital when they are extremely ill or have severe physical trauma. Patients enter inpatient care mainly from previous ambulatory care such as referral from a family doctor, or through emergency medicine departments. The patient formally becomes an "inpatient" at the writing of an admission note. Likewise, it is formally ended by writing a discharge note

\section{Patient satisfaction}

There is no consensus between the literatures on how to define the concept of patient satisfaction in healthcare. In Donabedian (2005), quality measurement model, patient satisfaction is defined as patientreported outcome measure while the structures and processes of care can be measured by patient-reported experiences. Many authors tend to have different perceptions of definitions of patient satisfaction. Jenkinson et al. (2003) and Ahmed et al. (2011) point out that patient satisfaction mostly appears to represent attitudes towards care or aspects of care. While Mohad et al. (2014) refers to patient satisfaction as patients' emotions, feelings and their perception of delivered healthcare services.

On the other hand, other authors define patient satisfaction as a degree of congruency between patient expectations of ideal care and their perceptions of real care received. Patient satisfaction include a number of elements including: low cost strategy to improve safety and quality in hospital (Boulding, et al., 2011), patients perceptions against professional skill and communication attitude of personnel, service quality and patient trust (Ching-Sheng, Su-Yueh, Yi-Ting, 2013) or waiting time for appointments, office waits, emergency care, availability of hospitals and other resources. According to Zaslavsky et al. (2000) patient satisfaction is one of the most important indicators of health care quality and is increasingly being used to assess the performance of health care organizations. Patient satisfaction is the extent to which patients are happy with their healthcare, both inside and outside of the doctor's office.

Quality of care form the patient's perspective and patient satisfaction are two major multidimensional concepts that are used several times interchangeably. Quality of care has a subjective profile as it involves a cognitive evaluation process and an objective determinant which is 'care' as an outcome, a process or a structure measure. On the other hand, patient satisfaction tends to have an objective profile and determinant which is patient's subjection. If we add the term 'perceived' to both terms (quality and satisfaction) we conclude to an opposite meaning result: perceived quality of care and perceived satisfaction become a totally subjective concept as they are based on patients' own feelings. As a result, patient satisfaction represents the new phenomena or the new 'paradigm' in the health care sector, after a long period of research experimentation. It could be necessary to use the term 'attributable' satisfaction in 
order to describe the extent of this phenomenon, as patient satisfaction is attributed to patient's perceived value of several care dimensions.

\section{Healthcare and patient satisfaction}

The healthcare industry is now shifting toward patient-centred care models. The paradigm suggests that improving patient-centered care and improved patient satisfaction will lead to better health outcomes. This has had significant impact on the structure of healthcare and has led to changes in priorities, goals, and objectives of many healthcare organizations.

In the wake of this, patients are demanding a bigger claim in their healthcare, and expect a certain level of service from their providers and healthcare organizations. As a result, providers need to fully understand patient satisfaction measures, how they affect their practices and how to adjust their strategic plans accordingly.

In Vocera's 2016 Rise of the Chief Experience Officer report, 64 percent of healthcare professionals state that their organizations value patient satisfaction just as much as they do patient safety and clinical workflow improvements. Since patients have assumed more of a consumer role in their own healthcare, hospitals and other organizations now need to ensure that their patients were happy with the care that they received and how they were treated as people. Supporting patient satisfaction can have a positive effect on several parts of the healthcare organization, including improving patient retention rates, securing a positive local reputation, and preventing possible malpractice lawsuits.

According to Dewa et al, (2016), this patient satisfaction model of healthcare has the potential to have a negative impact on the healthcare system as evidenced by decreased physician satisfaction and increased burnout.

\section{Patients' satisfaction and quality healthcare in the context of ghana}

Ghanaians perceive the quality of health services as sub-standard and therefore choose alternative sources of treatment (Turkson, 2009). The trust and confidence are undermined by frequent shortages of drugs and medical supplies, long queues, the absence of emergency services and poor staff behaviour. This has resulted in low utilization of health services despite the substantial investment aimed at improving access to health services in Ghana (Shield Workpackage Report, 2007; Gyapong et al, 2007).

However, others perceive the quality of healthcare in Ghana to be high. Turkson (2009), looked at the quality of healthcare delivery in a rural district of Ghana and found that generally the quality of healthcare delivery was perceived to be high for most of the indicators used. That is ninety percent of the respondents were satisfied or very satisfied with the care given during their visit to the health facility. The participants however perceived poor attitude of some health workers, long waiting times, high cost of services, inadequate staff, policy of payment for health services, frequent referrals to hospitals, and lack of ambulances at facilities as being detrimental to effective delivery of quality healthcare.

Furthermore, another study by Atinga et al (2011), examined how communication, provider courtesy, support/care, environment of the facility and waiting time significantly predict patients' satisfaction with the quality of healthcare in two hospitals located in northern Ghana. They observed that the five-factor model, support/care, environment of the facility and waiting time determine patients' satisfaction with quality of healthcare delivery. The explanatory power of the dependent variable was explained by 51 percent in the regression model. Peprah (2014) conducted a study at Sunyani Regional Hospital in Ghana to assess patient's satisfaction using the SERVQUAL model by Parasuraman et al, (1998). The SERVQUAL instrument was adapted and modified to capture the relevant data. A total of 214 patients were sampled for the study. The study analysed for descriptive statistics and patients' satisfaction were determined by the service quality gap. The study results indicate that the overall satisfaction of the patients concerning service quality of the hospital was good. Again, the study recommends policy action to improve service delivery in communication/interpersonal relationship, assurance and responsiveness dimensions. However, tangibility and empathy were esteemed high by patients in their satisfaction in assessing quality healthcare at Sunyani Regional Hospital. 
DOI: 10.21522/TIJMG.2015.SE.19.01.Art015

ISSN: 2520-310X

\section{Determinants of patient satisfaction}

It is observed that consumer satisfaction is a fundamental requirement for health care providers. Satisfaction is important when patients themselves and institutional health care service buyers make selection decisions. In addition to its positive impact on patient retention and customer loyalty, patient satisfaction influences the rates of patient compliance with physician advice. In order to understand various factors affecting patient satisfaction, researchers have explored various service quality dimensions considered by patients when evaluating health care quality, such as physician expertise, convenience, degree of concern shown by the physicians and other medical staff i.e. nurses and receptionists. According to Al-Abri \& Al-Balushi (2014), in the increasingly competitive market of healthcare industries, healthcare managers should focus on achieving high or excellent ratings of patient satisfaction to improve the quality of service delivery; therefore, healthcare managers need to characterize the factors influencing patient satisfaction which are used as a means to assess the quality of healthcare delivery.

In order to understand various factors affecting patient satisfaction, researchers have explored various dimensions of the perceived service quality, as meaningful and essential measures of patient perception of healthcare quality. Kaneet et al. (1997) and Marley et al. stated that measuring satisfaction should "incorporate dimensions of technical, interpersonal, social, and moral aspects of care". Research of patient satisfaction in advanced as well as developing countries has many common and some unique variables and attributes that influence overall patient satisfaction.

\section{Patient characteristics}

Most of the studies in the literature review examined the correlation between demographic factors such as age, gender, health status and level of education with patient satisfaction; however, the findings from these studies are conflicting. Two studies, one conducted in Scotland whereby 650 patients discharged from four acute care general hospitals during February and March 2002, and the second study was conducted in 32 different large tertiary hospitals in the USA; both showed that male patients, patients older than 50 years of age, patients who had a shorter length of stay or better health status and those with primary level education had higher scores related to variable health service-related domains. On the other hand, a national survey performed in different accredited hospitals of Taiwan found that patient characteristics such as age, gender and education level only slightly influenced patient satisfaction but that the health status of patients is an important predictor of a patient's overall satisfaction. In addition, Nguyen et al. (2002) and Jenkinson et al. (2002) declared from their studies that the two strongest and most consistent determinants of higher satisfaction are old age and better health status. While two studies reported contrary results regarding the influential effect of the two controlled variables (age and gender) on overall patient satisfaction in different aspects of healthcare services. In contrast, a 2006 national survey of 63 hospitals in the five health regions in Norway showed that age, gender, perceived health and education level were not significant predictors of overall patient satisfaction. These factors are not modifiable and are impractical for healthcare managers that are eager to improve patient satisfaction. These patient characteristics should be considered for fair adjustment of patient satisfaction studies in order to be utilized in benchmarking with other healthcare institutions.

\section{Health care settings/ clinical factors}

On the other hand, the researchers extensively discussed the multidimensional attributes of healthcare settings that were shown to be the most potent determinants for improving the overall patient satisfaction. Healthcare managers need to direct more efforts towards those highly ranked attributes and initiate some improvement strategies in other areas of health services that are unsatisfactory from the patient's perspective.

A remarkable outcome of four studies conducted in tertiary hospitals in different countries revealed that the nurses' courtesy, respect, careful listening and easy access of care was particularly the strongest driver of overall patient satisfaction. These aspects of nursing care are highly ranked by patients 
compared to other independent factors such as physician care, admission process, physical environment and cleanliness. In addition, a study carried out in 430 hospitals in the USA found the nurse work environment and patient-nurse staffing ratio had statistically significant effects on patient satisfaction and recommendations.

Otani et al. (2011), surveyed 32 different large tertiary hospitals in the USA to identify the relationship of nursing care, physician care and physical environment to the overall patient satisfaction and the results showed that all attributes were statistically significant and positively related to overall satisfaction; however, nursing care was the most critical to increase overall patient satisfaction. The researchers also found that the courtesy and respect of healthcare providers impact more on patient satisfaction while communication and explanation are the second most important aspect. In contrast, a survey conducted at 13 acute care hospitals in Ireland revealed that effective communication and clear explanation had the strongest impact in improving the overall patient satisfaction among other attributes of care. These findings provide evidence of the importance of the nursing role as the most significant determinant of overall patient satisfaction (Sweeney et al., 2003).

Three other studies found that interpersonal communication skills of physicians in terms of their attitude, explanation of conditions, level of care, emotional support, respect for patient preferences and involving patients in decision making were more influential factors than clinical competence and hospital tangibles on patient satisfaction (Cheng et al., 2003, Kim et al., 2004, Andrabi et al., 2012). However, a survey conducted in a tertiary care academic hospital in the USA showed that only $33 \%$ of physicians were rated as excellent for their communication behaviour which suggests that there is room for improvement in physician communication behaviour in the hospital to improve quality of care. In addition, the main outcome of a study using the data of 202 participants from general acute care hospitals in the USA, concluded that most determinants of patient satisfaction were related to communication, empathy and caring from hospital personnel (Kathryn et al., 2004).

According to Heath (2018), overall, patient satisfaction boils down to three points: communication, provider empathy, and care coordination. Patient loyalty is primarily driven by:

1. Communication- There is a difference between waiting and not knowing why you're waiting.

2. Empathy- Patients want to understand that we actually care for them. So, ability to be empathetic in delivery of care is incredibly important to patients.

3. And the last one is coordination of care. Patients want providers to work as a team.

Research shows that despite the technical quality of care delivered, provider empathy is the main teller of whether a patient will or will not be satisfied. Patients also perceive empathic care as technically better than less personal care. Even simple things like increasing eye contact with patients will boost satisfaction and engagement. In a recent survey published in the 'Patient Engagement Hit' - Healthcare Media, 59\% of patients reported that face-to-face time with their providers increased their engagement and satisfaction, (Heath, 2018).

\section{Non-clinical/ non-medical factors}

Regarding non-clinical factors, there are some contrary comments which were disclosed by Kui-Son et al (2005) regarding the aspects of hospital environment and amenities which scored lowest for a patient satisfaction index in a study carried out in out-patients departments in South Korea. Correspondingly, a study conducted in a public hospital in France found the most common problems experienced by patients were related to hospital living arrangements and amenities (Nguyen et al.2002). A similar result was reported in a study conducted at five hospitals served under the BJC Healthcare System (Otani et al. 2011). Furthermore, Arshad et al. (2012) reported that the major dissatisfaction in an out-patients department was the long waiting time and overcrowded registration. In contrast, a study carried out in five different hospitals in Scotland found that physical comfort had the highest satisfaction rate compared to other core dimensions: information, coordination of care and emotional support (Jenkinson et al. 2002). 
DOI: 10.21522/TIJMG.2015.SE.19.01.Art015

ISSN: 2520-310X

Many situations may influence patient satisfaction such as, waiting time to receive the medical care services, availability of convenience facilities in hospitals and doctor-patient communication and interaction. A study by Okotie et al. (2008) states that waiting time to access health care may be associated with the patient's socio-economic background, as the wealthy patients usually do not want to wait for a longer time and exert pressure to receive early appointments. But poor patients have no other option but to wait for a longer time. Waiting time for a patient is in fact the time spent waiting for a consultant and it can be said that if the consultation process is undertaken in a timely manner as perceived by the patients, it will give results of more satisfied patients, however, if the process is delayed patients may get upset and frustrated, which will thus reduce their satisfaction to a great deal. Expectations of the patients, service quality and patient satisfaction may also vary across different levels of Hospitals.

\section{Patient satisfaction in outpatient and inpatient settings}

According to Mosadeghrad (2014), although both academia and practitioners agree on the importance of measuring patient satisfaction, the findings differ on the suggested factors that influence the satisfaction level of patients. While a number of studies have suggested that there is an association between the hospital characteristics [such as administration, management, environment and settings] and patient's characteristics [demographic and socio-economic factors and health status], with the patient satisfaction, another strand of research has found that subjective experiences of received care and service and health status are stronger predictors of patient satisfaction compared to socio-demographic determinants. The differences in the findings may be due to national and culturally constrained factors

A detailed survey was conducted by Lee (2005) to test outpatients in dental clinics which were available in the greater Daegu area of Korea and he differentiated medical services quality into: (i) treatment, (ii) professionalism, (iii) courtesy, (iv) convenience, and (v) comfortableness. Hence, factors involving medical services quality in Hospitals vary considerably depending upon the various kinds i.e (dentist department versus general department) and the types i.e. (inpatient in Hospitals versus outpatient in Hospitals) of medical services provided.

Rao et al., (2006) surveyed inpatients and outpatients who visited primary health centers, community health centers, district hospitals and female district hospitals in the state of Uttar Pradesh, the most populous state of India. They identified five dimensions of service quality -medicine availability, medical information, staff and doctor behaviour and hospital infrastructure. Patients' perception of service quality was found to be marginally better than average. For outpatients, doctor behaviour was the key determinant of patient satisfaction.

Kumari et al. (2009), examined patients attending the outpatient department (OPD) of government allopathic health facilities of Lucknow district, the capital city of Uttar Pradesh.

Although the overall satisfaction of the patient was satisfactory, there were deficiencies in certain areas such as short OPD hours, availability of drinking water, availability of clean toilets and doctor-patient communication.

Sharma et al (2004) assessed the patient satisfaction level visiting the OPD in a premier multi-specialty hospital of North India and concluded that the patients were satisfied with the doctor, nurses and paramedical staff. However, a certain percentage of patients opined that doctors had shown little interest to listen to patients' problems and often used technical terms to explain their illness or consequences. The majority of the patients in the survey were satisfied with the basic amenities, but the services were found costly.

Mekoth et al., (2012), studied the OPD of a public hospital in Goa and observed the quality of physicians and clinical support staff as key determinants of patient satisfaction. However, the quality of non-clinical staff was not found to affect patient satisfaction.

\section{Factors that influence patient satisfaction or dissatisfaction}

Boonshoof and Gray (2004) conducted studies on the relationships between service quality, customer satisfaction and buying intentions in the private hospital industry. Their study attempted to assess what 
dimensions of both customer satisfaction and service quality drive 'Overall Satisfaction and Loyalty' in the South African private hospital industry. The results revealed that the service quality dimensions, empathy of nursing staff and assurance impact positively on both loyalty and cumulative satisfaction. The results also revealed that the customer satisfaction dimensions are: satisfaction with food, satisfaction with the nursing staff and satisfaction with the tariff. All these affects positively on both loyalty and satisfaction. The survey and study conducted, aimed to investigate the relationship between outpatient satisfaction and service quality dimensions where patients have substantial freedom in choosing their medical service providers. Results show that the pattern of relationships between service quality and patient satisfaction was similar across the gender, age and service type subgroups; it was an exploratory study on service quality.

Themes showing patient satisfaction with healthcare delivery in India were conducted by Sachin Kamble (2007) who has stated that very little emphasis was given by patients on service quality dimensions. The aim of the research was to get an idea of patient's interpretations of satisfaction.

A detailed study was done by Hardeep Chahal (2004) of Ahmedabad Civil Hospital, which showed that the more satisfied the patients are with the quality of interactions with staff, more likely they will opt for treatments for similar and different medical problems and would recommend the hospital to their friends and relatives. Patients basically from pediatric, obstetrics and gynecology had been selected for the study. Results stated that it is necessary to capture information on patient's needs, expectations and perceptions. Main concerns of patients relate to being treated with dignity and respect, given clear information and psychological support. Older patients tended to be more satisfied with medical care services than their younger counterparts.

Patient satisfaction according to March S, Swart E, Robra B (2006) is an important indicator in evaluating the quality of the patient satisfaction (care) in the outpatient department. In a study conducted at Mageburg, Germany only 3.6\% of patients were dissatisfied. Thorne L, Ellamushi (2002) at the Neurosurgical care department of National Hospital, London, observed that most aspects of patient care had 70 to $80 \%$ satisfaction.

Laurent et al. 2006 conducted a study in a tertiary teaching hospital in France aiming to assess the opinions of clinical staff towards the effect of in-patient satisfaction surveys on the quality improvement process. A favourable result of $94 \%$ revealed that the patient was able to judge hospital service quality, especially in its relational, organizational and environmental dimensions.

\section{Why Is patient satisfaction important to hospitals?}

A measure of care quality, patient satisfaction gives providers insights into various aspects of medicine, including the effectiveness of their care and their level of empathy. These days, delivering topnotch medical care involves more than just helping the patient get well — it also encompasses the overall patient experience. Specifically, it's crucial to assess the patients' level of satisfaction with their treatment. Healthcare organizations are taking notice. Several studies indicate ensuring maximum patient satisfaction in their facilities is a top priority of hospital executives throughout the United States (Gallagher Healthcare, 2018)

According to Gallagher Healthcare (2018) from a business perspective, patient satisfaction matters for several reasons, including:

- Building loyalty: In today's ultra-competitive healthcare environment, hospitals must do everything possible to ensure their patients continue to choose them as their medical treatment providers. A satisfied patient is more likely to keep the same hospital than search for another facility.

- Attracting new patients: As the old marketing adage goes, word of mouth is the best form of advertising. People who are satisfied with their hospital stay are more likely to tell others about their experience, which can help healthcare facilities to keep new patients coming through the doors. 
DOI: 10.21522/TIJMG.2015.SE.19.01.Art015

ISSN: 2520-310X

- Improving clinical outcomes: Studies indicate a direct correlation between patient satisfaction and the effectiveness of treatment. Hospital physicians and staff members who can build trust will increase the likelihood of the patient adhering to their treatment recommendations.

- Minimizing the risk of litigation: Some medical literature indicates patients who are satisfied with the level of care provided by a hospital are less likely to sue if they experience an unsatisfactory clinical outcome.

The reviewed literature agreed on the fact that there is an impact of measuring patient satisfaction on quality improvement of care. Patients' evaluation of care is a realistic tool to provide opportunity for improvement, enhance strategic decision making, reduce cost, meet patients' expectations, frame strategies for effective management, monitor healthcare performance of health plans and provide benchmarking across the healthcare institutions (Al-Abri \& Al-Balushi, 2014).

In addition, due to the tendency of healthcare industries to concentrate on patient-centered care; patient satisfaction reflects patients' involvement in decision making and their role as partners in improving the quality of healthcare services. Mohan et al (2011) also deemed the significant correlation between measuring patient satisfaction and continuity of care where the satisfied patients tend to comply with the treatment and adhere to the same healthcare providers. Patient satisfaction represents a key marker of communication and health-related behavior. In contrast, some of the literature dismisses patients' views as a wholly subjective evaluation and an unreliable judgment of the quality of care.

\section{Conclusion remarks}

It is noticed that patient's perception about health care systems seems to have been largely ignored by healthcare managers in developing countries. Patient satisfaction depends upon many factors such as: quality of clinical services provided, availability of medicine, attitude, behaviour of doctors and staff, cost of services, hospital infrastructure, physical comfort, emotional support and respect for patient preferences. All these factors can be categorized into clinical and non-clinical factors. Therefore, both clinical and non-clinical factors influence patient satisfaction. Mismatch between patient expectation and the service received is related to decreased satisfaction. Therefore, assessing patient's perspectives according to World Health Organization, Report (2000), gives them a voice which can make private and public health services more responsive to people's needs and expectations.

There are very few studies in Ghana that measure patient satisfaction with the services provided by the healthcare organizations (clinical and non-clinical services). Patient satisfaction surveys are useful in gaining an understanding of user's needs and their perception of the services received. Patients attending each hospital are responsible for spreading the good image of the hospital and hence the satisfaction of the patients attending the hospitals is equally important for the hospital management. Surveys of outpatient's services (OPD) have elicited problems like overcrowding, delay in consultation, proper behaviour of staff, logistic arrangements, support services, nursing care, doctor's consultation, etc. However, there is little or no survey conducted on inpatient department especially in Ghana. There is therefore the need for researchers to conduct studies on patient satisfaction and its determinants in outpatient and inpatient departments and also how non-clinical factors influence patient satisfaction.

\section{References}

[1]. Aduo-Adjei KO (2015). Patients Satisfaction with Quality Healthcare in Ghana: A Comparative Study between University of Ghana and University of Cape Coast Hospitals [dissertation]. Ghana: University of Ghana.

[2]. Ahenkan, A., Aduo-Adjei, K. (2017). Predictors of Patient Satisfaction with Quality of Healthcare in University Hospitals in Ghana. Hospital Practices and Research., 2(1), 9-14.

[3]. Al-Abri, R., \& Al-Balushi, A. (2014). Patient satisfaction survey as a tool towards quality improvement. Oman medical journal, 29(1), 3-7.

[4]. Ahmed, M.M., Al-Hawary, S. I., \& Alghanim, S.A. (2011). Quality level of health care service provided by King Abdullah educational hospital from patient's viewpoint. Journal of Contemporary Research in Business, 2(11), $552-572$. 
[5]. Andrabi S. A., Hamid S., Rohul, J.\& Anjum F. (2012). Measuring patient satisfaction: A cross sectional study to improve quality of care at a tertiary care hospital, Health line, Vol. 3, NO. 1, pp. 59-62.

[6]. Ayimbillah Atinga R, Abekah-Nkrumah G, Ameyaw Domfeh K. (2011). Managing healthcare quality in Ghana: a necessity of patient satisfaction. Int $J$ Health Care Qual Assur;24(7):548-563. doi: $10.1108 / 09526861111160580$.

[7]. Baalbaki, Imad \& Ahmed, Zafar \& Pashtenko, Valentin \& Makarem, Suzanne. (2008). Patient satisfaction with healthcare delivery systems. International Journal of Pharmaceutical and Healthcare Marketing., 2, 47-62.

[8]. Boshoff, C., and B. Gray. (2004). The Relationship between Service Quality, Customer Satisfaction and Buying Intentions in the Private Hospital Industry. "South Africa Journal of Business Management 35 (4): 27-37.

[9]. Cheng SH, Yang MC, Chiang TL (2003). Patient satisfaction with and recommendation of a hospital: effects of interpersonal and technical aspects of hospital care. Int J Qual Health Care.

[10]. Desta, H., Berhe, T., \& Hintsa, S. (2018). Assessment of patients' satisfaction and associated factors among outpatients received mental health services at public hospitals of Mekelle Town, northern Ethiopia. International journal of mental health systems, 12, 38. doi:10.1186/s13033-018-0217-z.

[11]. Dewa CS, Loong D, Bonato S, et al (2016). The relationship between physician burnout and quality of healthcare in terms of safety and acceptability: a systematic review BMJ Open 2017;7:.e015141. doi: 10.1136/bmjopen-2016-015141.

[12]. Donabedian, A (2005). Evaluating the Quality of Medical Care, The Milbank Quarterly, 83(4):691- 729.

[13]. Essiam, J. (2013), Service quality and patient's satisfaction with healthcare delivery: empirical evidence from patients of the outpatient department of a public university hospital in Ghana., European Journal of Business Management, 5(28), 52-59.

[14]. Gallagher Healthcare (2018). The Importance of Patient Satisfaction in Healthcare. Available online at https://www.gallaghermalpractice.com/blog/post/the-importance-of-patient-satisfaction-in-healthcare.

[15]. Gyapong, J., Garshong, B., Akazili, J., Aikins, M., Agyepong, I., \& Nyonator, F. (2007). Critical Analysis of Ghana"s Health System: With a focus on equity challenges and the National Health Insurance. SHIELD Work package 1 Report NDPC.

[16]. Heath, S. (2018). Patient Satisfaction and HCAHPS: What It Means for Providers. Patient Engagement Hit, https://patientengagementhit.com/features/patient-satisfaction-and-hcahps-what-it-means-for-providers.

[17]. Jenkinson C, Coulter A, Bruster S, Richards N, Chandola T. (2003). Patients' experience and satisfaction with Health Care: Results of a questionnaire study of specific aspects of care. Quality Safety Health Care, VOL 2003;11:335-339.

[18]. Kathryn, A., M., David A., C., Susan, M., G. (2004). The Role of Clinical and Process Quality in Achieving Patient Satisfaction in Hospitals, Decision Sciences, Vol: 35, NO.3, pp.349-369.

[19]. Kim SS, Kaplowitz S, Johnston MV (2004). The effects of physician empathy on patient satisfaction and compliance. Eval Health Prof. 27(3):237-51.

[20]. Kui-Son Choi, Hanjoon Lee, Chankon Kim, Sunhee Lee, (2005). "The service quality dimensions and patient satisfaction relationships in South Korea: comparisons across gender, age and types of service", Journal of Services Marketing, Vol. 19, NO. 3pp. 140 - 149[online], available at http//dx..org/10.1108/08876040510596812.

[21]. Kumari, R., Idris, M., Bhushan, V., Khanna, A., Agarwal, M., \& Singh, S. (2009). Study on patient satisfaction in the government allopathic health facilities of Lucknow district, India. Indian Journal of Community Medicine, 34(1), 35-51.

[22]. Laurent, B., Patrice, F., Elisabeth D., Georges, W. \& Jose, L. (2006). Perception and use of the results of patient satisfaction surveys by care providers in French teaching hospital, International Journal for Quality in Health Care 2006; Vol:18, NO. 5, pp. 359-364.

[23]. Mekoth, N, G. Babu, Y., Dalvi, N. Rajanala, K. \& Nizomadinov, C. (2012). Service encounter related process quality, patient satisfaction and behavioural. Intentional Journal of Management, 6(4), 333-350.

[24]. MOH (2007). Quality Healthcare Delivery Assessment Report. Accra: Ministry of Health.

[25]. Mohad, A., \& Chakravarty, A. (2014). Patient satisfaction with services of the outpatient department. Medical journal, Armed Forces India, 70(3), 237-42. 
DOI: 10.21522/TIJMG.2015.SE.19.01.Art015

ISSN: 2520-310X

[26]. Mosadeghrad, A. M. (2014). Factors influencing healthcare service quality. International journal of health policy and management, 3(2), 77-89. doi:10.15171/ijhpm.2014.65.

[27]. Nguyen Thi, Briancon, Empereur and Guillemin. (2002). Factors determining inpatient satisfaction with care. Social Science \&Medicine, 54, pp. 493-504.

[28]. Okotie, O.T., Patel, N. and Gonzalez, C.M. (2008). The effect of patient arrival time on overall wait time and utilization of physician and examination room resources in the outpatient urology clinic, Advances in Urology, available at: http://downloads.hindawi.com/journals/ au/2008/507436.pdf.

[29]. Otani K, Herrmann PA, Kurz RS. (2011). Improving patient satisfaction in hospital care settings. Health Serv Manage Res 2011 Nov;24(4):163-169.

[30]. Parasuraman, A., Zeithaml, V. A. and Berry, L. L. (1988). „SERVQUAL: A Multiple Item Scale for Measuring Consumer Perceptions of Service Quality"e, Journal of Retailing, Vol. 64, No. 1, pp. 12-40.

[31]. Peprah, A.A. (2014). Determinant of Patients "e Satisfaction at Sunyani regional Hospital. Ghana International Business and Social Research, 4(1), 96-108.

[32]. Rao, M. Clarke, A. Sanderson, C. \& Hammersley R. (2006). Patients' own assessments of quality of primary care compared with objective records-based measures of technical quality of care: Cross Sectional Study. British Medical Journal, 33(19), 355-375.

[33]. Sanjeewa G.G.C, Senevirathne R.S. (2017). Patient Satisfaction with Health Care Services Delivered at the Out Patients Department-Case Study-at Teaching Hospital Karapitiya Sri Lanka. Health Care Current Reviews, 5, 193.

[34]. Sharma, R.D., and Gupta, M. (2004). Patient satisfaction in public outpatient health care services. The Journal of Health Management, 6(1), 23-45.

[35]. Sweeney J, Brooks A.M, Leahy A (2003). Development of the Irish National Perception of Quality of Care Survey. Int J Qual Health Care. 15(2):163-8.

[36]. Turkson, P.K. (2009). Perceived quality of healthcare delivery in a rural district of Ghana. Ghana Medical Journal, 43(2), 65-70.

[37]. Zaslavsky, A.M., Beaulieu, N.D., Landon, B.E. and Cleary, P.D. (2000). Dimensions `of consumer-assessed quality of Medicare managed-care health plans, Medical Care, Vol. 38 No. 2, pp. 162-74. 